\title{
EDITORIAT
}

\section{Enfermería. Una profesión en continuo movimiento}

Desde su nacimiento como actividad hasta la obtención de un espacio propio en el mundo de la Ciencia, el camino de una profesión pasa por muchas etapas.

Algunas más sencillas, otras más complejas. En ocasiones se experimentan retrocesos...avances rápidos....diría que la vida misma en cada entorno social.

Si observamos la evolución de la profesión Enfermera y su camino hacia el desarrollo científico, podemos encontrar su propia singularidad y desde luego ser optimistas por el camino recorrido y las perspectivas de futuro.

Permítanme en este editorial una reflexión.

No es sencillo consolidarse como Ciencia, cuando existe un contraste profesional en el mundo que, hay que, tener en consideración.

Trataremos de resumir esta reflexión.

Para cubrir un espacio científico, hay que tener un espacio profesional propio. Espacio profesional propio significa, formación, gestión e investigación autónomas unido a toma de decisiones específica sobre un objeto de estudio que tenga repercusión social. 
La autonomía en Investigación y Docencia se obtiene a partir del momento en el que una profesión tiene la capacidad de obtener el máximo grado académico en Enfermería desde Enfermería. En Gestión la autonomía, no siempre está vinculada al Grado académico o a la formación propia. Cada Empresa, tiene sus propios criterios de selección de gestores.

La obtención del grado académico de Doctor, tan importante en Investigación y docencia se encuentra en momentos bastante desiguales en diferentes partes del mundo. En España el grado de Doctor (desde Enfermería) se puede obtener desde 2006; en E.E.U.U. y Canadá desde hace aproximadamente un siglo y en muchos países ni se lo están planteando.

Sin embargo, la autonomía para tomar decisiones en la asistencia sanitaria que, supone el $90 \%$ de la profesión, está presente en cualquier entorno.

La función de las Enfermeras vinculada al cuidado se conoce desde los albores de la humanidad. La toma de decisiones sobre déficit de autonomía hace que, la Enfermería tenga un gran espacio social desde siempre que, en ocasiones puede hacerse algo invisible.

El desarrollo académico y especializado, ha de servir para profesionalizar el cuidado y evaluar acciones que contribuyan a la toma de decisiones clínicas, es decir que, apoye una Enfermería asistencial de calidad.

La gestión es crucial para cuidar a quien cuida. Un enfermero, no puede ser mano de obra barata o personal cambiante en organizaciones que no siempre miran hacia las personas. Cuidar al cuidador, es hacerle sentir importante dentro de una organización; fomentar la toma de decisiones y respaldarla. Solo a partir de ese momento, cuando las enfermeras se perciban importantes, será cuando realmente sean importantes.

Respecto a la formación universitaria, es pertinente que, igual que sucede en el resto de titulaciones universitarias, la formación se dirija por Enfermeras comprometidas que, sepan abrirse camino en una Institución que, tiene más de 800 años de historia, donde los "nuevos" títulos no son vistos siempre con buenos ojos, porque en ocasiones se viven desde la Universidad 
como una amenaza. En este espacio universitario, la actitud de los responsables es crucial. Si se dejan llevar por la influencia de otras disciplinas que tienen más poder en este mundo complejo, estarán vendiendo a la Enfermería por un plato de lentejas.

La investigación es el elemento protector de una profesión. Su transversalidad debe tener forma de actitud. Una actitud hacia la búsqueda de la evidencia científica para tomar decisiones, la curiosidad por detectar problemas y buscar soluciones, enseñar con argumentos y aplicar resultados de estudios realizados por Enfermeras para ser utilizados por Enfermería hacia los pacientes. Esta actitud, contribuirá a marcar el espacio científico que necesita la profesión para posicionarse en el mundo de la Ciencia.

La Enfermería asistencial es, la realmente importante. Los gestores, docentes e investigadores debemos apoyarla.

Quien impacta sobre la sociedad, son las Enfermeras clínicas. Quien forma en un $50 \%$ a los estudiantes, son las Enfermeras clínicas. Quien aplica o no, los resultados de las investigaciones, son las Enfermeras clínicas.

Quien debe pactar con las gestoras son las Enfermeras clínicas y quien le debe exigir a sus representantes colegiales y sindicales, un corporativismo en términos de igualdad......son las Enfermeras clínicas.

RECIEN editorial 